\title{
EFEITO DO IMPLANTE INTRAVAGINAL DE PROGESTERONA SOBRE A CICLICIDADE DE ÉGUAS EM ANESTRO DA RAÇA QUARTO DE MILHA
}

\author{
OLIVEIRA FILHO, Luis Ricardo de ${ }^{1}$ \\ DANEZE, Edmilson Rodrigo ${ }^{2}$ \\ D'AURIA, Eliana ${ }^{3}$ \\ SCHUTZER, Carlos Guilherme de Castro ${ }^{4}$
}

RESUMO: O presente estudo teve como objetivo acompanhar a dinâmica folicular de dez éguas submetidas à inserção do dispositivo de liberação lenta de progesterona e, verificar se este procedimento antecipa o início da ciclicidade ovariana em éguas em anestro. Para isso, foram colhidos dados do uso de implante intravaginal de progesterona em éguas que se encontravam em anestro. Após dez dias da colocação do implante, o mesmo foi removido e administrado $0,25 \mathrm{mg}$ de prostaglandina F2 $\alpha$ por via intramuscular. As éguas foram diariamente acompanhadas, por meio de exame ultrassonográfico, até o folículo ovariano apresentar-se com 35 mm de diâmetro para se administrar hCG e GnRH e, no dia seguinte, realizar-se a inseminação artificial e aguardar a ovulação. Oito dias após a ovulação foi realizada a coleta dos embriões. Dentro das condições do presente experimento, concluímos que a utilização do implante intravaginal de progesterona sobre a ciclicidade das éguas em anestro demonstrou $80 \%$ de eficácia, conseguindo-se $75 \%$ de embriões viáveis. Podemos concluir, também, que a faixa etária das éguas não influenciou a eficácia do implante, já que éguas com idade entre três e 25 anos foram responsivas ao uso do implante intravaginal de progesterona.

Palavras-chave: Éguas. Ultrassonografia. Reprodução. hCG. GnRH.

\section{EFFECT OF INTRAVAGINAL PROGESTERONE IMPLANT CYCLICALITY ON OF MARES IN ANESTROUS QUARTER MILE RACE}

\begin{abstract}
SUMMARY: The purpose of the present paper was following up the follicular dynamic of ten mares submitted to the insertion of the device for slow liberation of progesterone and, knowing whether or not it accelerated the beginning of the ovarian cyclicity in mares in anestrus. For that reason, were collected data about the use of progesterone intravaginal implantation were in anestrus. 10 days after the implantation placement, the same was removed and it was administered prostaglandin F2 $\alpha$. The mares were followed up through US till the follicles were $35 \mathrm{~mm}$ of diameter to administer human chorionic gonadotropin (hCG), in order to, on the following day, accomplishing the IA and waiting for ovulation. Then, after eight days it was accomplished the embryos collection. Within the conditions of the present experiment, we've concluded that using the progesterone intravaginal implantation on the cyclicity of mares in anestrus has demonstrated $80 \%$ of efficacy, making it possible obtaining $75 \%$ of viable embryos. We can conclude also that, the mares age group hasn't influenced the implantation efficacy, since the mares between 3 and 25 years old were responsive to the use of progesterone anestrus.
\end{abstract}

Keywords: Mares. Ultrasonography. Reproduction. hCG. GnRH.

\footnotetext{
${ }^{1}$ Graduando em Medicina Veterinária. Faculdade Dr. Francisco Maeda, Ituverava-SP

2 Aprimorando em Medicina Veterinária. Faculdade Dr. Francisco Maeda, Ituverava-SP

${ }^{3}$ Professora Mestre. Departamento de Reprodução Animal. Faculdade Dr. Francisco Maeda, Ituverava-SP

${ }^{4}$ Médico Veterinário Autônomo. Centro Avançado de Reprodução Equina (Embrio Equi), São Simão-SP
} 


\section{INTRODUÇÃO}

A equideocultura brasileira ocupa posição de destaque internacional não só pelo expressivo número de animais, mas sendo a segunda maior população de equinos puros de raça do mundo, como também pela excelência do seu plantel. Assim sendo, a indústria do cavalo é uma importante área geradora de empregos e divisas para o Brasil.

Existem muitas razões pelas quais se faz necessário a busca de novos protocolos para que as éguas possam entrar em estro e obter seus produtos o quanto mais próximo possível do inicio do ano hípico. Nesse contexto, o Brasil é hoje um país de referência no estudo e na utilização de biotécnicas de reprodução assistida como a inseminação artificial, transferência de embriões, transferências de oócito, inseminação intracitoplasmática e clonagem; despertando grande interesse entre criadores e associações de criadores de cavalos.

A atividade reprodutiva dos equinos está diretamente relacionada com a duração da luminosidade do dia. Nas latitudes tropicais, animais expostos à luz natural ao longo do ano usualmente mostram duas fases reprodutivas, estro e diestro, separadas por um período transicional na qual ocorrem mudanças na atividade ovariana e das gonadotrofinas (NUNES et al., 2002).

As éguas se reproduzem no período do ano que oferece um melhor suplemento nutricional e as melhores condições de sobrevivência para os potros, ou seja, a incidência de ovulações é mínima ou ausente durante o inverno, aumenta transicionalmente durante a primavera, e é máxima durante o verão, e diminui transicionalmente durante o outono (GINTHER, 1992).

A melatonina é considerada a chave do controle da reprodução sazonal e tem sido demonstrado que a glândula pineal é quem controla o mecanismo dessa sazonalidade traduzindo os sinais fotoperiódicos registrados no olho através do nervo óptico para sinais endócrinos, através da melatonina. Em éguas, concentrações elevadas de melatonina são associadas com a fase escura. A secreção de melatonina aumenta no início da fase escura (noite) e diminui rapidamente no final da fase escura (amanhecer). Uma pequena exposição à luz durante a fase escura resulta em uma diminuição imediata na concentração de melatonina seguida pelo seu retorno quando a exposição à luz termina (GUILLAUME; PALMER, 1991).

Com relação ao estado nutricional, foi demonstrado que éguas que estão em boa condição corporal, em geral, iniciam a estação reprodutiva mais precocemente do que éguas com baixo escore corporal. No entanto, éguas em condições corporais ruins, que recebem uma suplementação alimentar, tem a primeira ovulação da estação mais precocemente do que éguas sem suplementação (KUBIAK et al., 1987).

Carnavale; Ginther (1997) demonstraram o efeito benéfico do pastoreio no inicio da atividade ovariana, ou seja, éguas em anestro pastando em verdes pastos desde o mês de maio ovulam mais cedo do que éguas estabuladas.

O mais comum e mais confiável método de indução da atividade ovariana é o fotoperíodo 
artificial e a maioria dos trabalhos realizados utiliza este tratamento, onde demonstra que o fotoperíodo artificial, simulando dias mais longos, pode ser usado para adiantar o tempo da primeira ovulação do ano (DAELS, 2004).

$\mathrm{O}$ uso de progesterona exógena em éguas tem se limitado aos protocolos empregados em receptoras e doadoras de embriões acíclicas, nos períodos de anestro e transição antecedendo a estação reprodutiva. Durante a estação, a progesterona é utilizada em receptoras recém-ovuladas buscando aumentar os índices de gestação do segundo ao quarto dia pós-ovulação. No entanto, o uso deste hormônio na sincronização de cio e ovulação tem sido pouco empregado quando comparado a grandes e pequenos ruminantes, sendo escassas as informações sobre dinâmica folicular em éguas submetidas à progesterona via mucosa vaginal (FERREIRA et al., 2009).

Nesse contexto, o presente estudo teve como objetivo acompanhar a dinâmica folicular de dez éguas submetidas à inserção do dispositivo de liberação lenta de progesterona e verificar se este procedimento antecipa o início da ciclicidade ovariana de éguas em anestro.

\section{MATERIAL E MÉTODOS}

O presente trabalho foi realizado durante o período de 30 de agosto de 2009 a 12 de fevereiro de 2010 no Centro Avançado de Reprodução Equina (Embrio Equi), localizado no município de São SimãoSP. Para isso, foram coletados dados referentes ao uso de implante intravaginal de progesterona (Cronipres®-Biogenesis, Brasil) em 10 éguas que se encontravam em anestro, sendo as mesmas da raça Quarto de Milha e com idade variando entre 3 e 25 anos.

As éguas foram mantidas em piquetes coletivos, com livre acesso a água e suplementadas com ração duas vezes ao dia em um total de dois $\mathrm{kg} /$ animal. Ressaltando que todas as éguas estavam devidamente vacinadas e vermifugadas.

Antes da colocação do implante, as éguas foram avaliadas por meio de exame ultrassonográfico com o intuito de avaliar as condições uterina e ovarianas. A ausência de corpo lúteo foi utilizada como critério de inclusão no experimento.

Após a avaliação e confirmado o anestro, foi introduzido o implante intravaginal de progesterona em cada égua. Com intuito de prevenir uma possível vaginite, previamente foi borrifada substância a base de terramicina e hidrocortisona (Terra-Cortril Spray®) no mesmo.

Passados dez dias, o implante foi removido e administrada $0,25 \mathrm{mg}$ de prostaglandina F2 $\alpha$ por via intramuscular, a partir desse momento as éguas foram avaliadas diariamente por meio de exame ultrassonográfico até ser evidenciada a presença de folículo de $35 \mathrm{~mm}$.

Evidenciado o folículo de $35 \mathrm{~mm}$, administrou-se $1.500 \mathrm{UI}$ de hCG associado a 1,0 mg de GnRH (Deslorelina). No dia seguinte à administração de hCG e GnRH as éguas foram inseminadas, sendo diariamente avaliadas por meio de exame ultrassonográfico até a ovulação. Confirmada a ovulação, aguardou-se oito dias para a realização da coleta dos embriões resultantes. 


\section{RESULTADO E DISCUSSÃO}

No exame ultrassonográfico realizado antes da colocação do implante observou-se que as dez éguas não apresentavam corpo lúteo detectável em nenhum dos dois ovários, sendo o mesmo protocolo utilizado por Carmo et al. (2009) ao realizar o mesmo procedimento em experimento com 20 éguas. Isso porque éguas em anestro apresentam baixas concentrações de LH, sendo que essa concentração aumenta conforme a égua entra em transição para o período de estro, no qual níveis elevados de LH são essenciais para indução da maturação do folículo e da ovulação (HAETINGER et al., 2008). Baseado nisso, foi colocado o implante intravaginal de progesterona nas dez éguas selecionadas para o experimento.

Arbeiter et al. (1994), mantiveram o implante intravaginal de progesterona por um período 10 a 12 dias, contudo, em nosso experimento foi preconizado a permanência do mesmo por 10 dias, já que Carmo et al. (2009) mostraram que o implante intravaginal foi capaz de induzir altos níveis de progesterona plasmática durante o período de 10 dias. Vale ressaltar que não foram percebidas reações adversas nos animais.

Foi administrado $0,25 \mathrm{mg}$ de prostaglandina $2 \alpha$ por via intramuscular, com a finalidade de luteólise de qualquer corpo lúteo pré-existente ou persistente na égua, além de induzir uma nova onda folicular na mesma (HAETINGER et al., 2008).

Após a retirada do implante, os folículos de sete éguas apresentaram-se com $35 \mathrm{~mm}$ em média de 3,8 dias, variando de 2 a 6 dias, entretanto, uma das éguas levou 20 dias para alcançar esse patamar, elevando a média do grupo para 5,8 dias (tabela 1).

As éguas ovularam em média 7,8 dias (tabela 1) após a retirada do implante de progesterona. Contudo, Carmo et al. (2009), sincronizando as ovulações também com implante intravaginal de progesterona em éguas, descreveram que a ovulação ocorreu em média 6 dias após a retirada do dispositivo.

Tabela 1. Acompanhamento (em dias) da dinâmica folicular para obtenção de folículo de $35 \mathrm{~mm}$ e ovulação de éguas em anestro depois de retirada de implante de progesterona. Embrio-Equi. São Simão-SP. 2010.

\begin{tabular}{cccc}
\hline \multirow{2}{*}{ Animal } & \multicolumn{3}{c}{ Período (dias) } \\
\cline { 2 - 5 } & Folículo de 35 mm & Ovulação & Indução - ovulação \\
\hline 1 & 4 & 6 & 2 \\
2 & 4 & 6 & 2 \\
3 & 5 & 7 & 2 \\
4 & 6 & 8 & 2 \\
5 & 3 & 5 & 2 \\
6 & - & - & - \\
7 & 3 & 5 & 2 \\
8 & 2 & 4 & - \\
9 & - & - & 2 \\
\hline Média & 20 & 22 & \\
Desvio Padrão & $\mathbf{5 , 8 7 5}$ & $\mathbf{7 , 8 7 5}$ & \\
\hline
\end{tabular}


Quando administrado em éguas, o hCG reduz a duração do estro e favorece que a ovulação ocorra em até 48 horas pós-indução (SQUIRES, 2008). Neste experimento, a administração de hCG ocorreu quando os folículos alcançaram diâmetro de $35 \mathrm{~mm}$, com isso todas as éguas ovularam dois dias após esse procedimento (tabela 1), denotando o mesmo princípio previsto por BARTOLI (2009) que, usando 15 éguas, concluíram que 50\% delas ovularam 48 horas após a aplicação do hCG.

Por apresentar efeito fisiológico semelhante ao LH e apresentar meia-vida em torno de 10 horas, a hCG vem sendo utilizado como hormônio indutor de ovulação, pois ele promove a maturação e ovulação de folículos de forma sincrônica, sendo provavelmente um dos hormônios mais utilizado no manejo da reprodução equina. Quando administrado em éguas, a hCG reduz a duração do estro e aumenta o número de animais que ovulam em até 48h pós-indução (SQUIRES, 2008). Segundo Berezowski et al. (2004), a administração de hCG é eficaz em 80 \% dos casos quando o folículo pré-ovulatório é detectado com pelo menos $35 \mathrm{~mm}$ de diâmetro. O hCG também se mostra eficiente para acelerar a maturação do oócito (PERES et al., 2006), devido ao fato de apresentar efeito fisiológico semelhante ao LH, pois sua utilização promove a maturação e ovulação de folículos de forma sincrônica (SQUIRES, 2008).

No presente experimento obtivemos $80 \%$ de eficácia do implante intravaginal de progesterona sobre a ciclicidade das éguas em anestro (tabela 2), contudo Arbeiter et al. (1994) conseguiram 93\% de eficácia num total de 29 éguas, sendo que 12 delas foram tratadas durante a estação de monta e 17 durante o período de outono/inverno.

Tabela 2. Eficácia do implante de progesterona sobre a ciclicidade e fertilidade de éguas em anestro. Embrio-Equi. São simão-SP. 2010.

\begin{tabular}{cccc}
\hline Animal & Idade & Eficácia do implante & Embrião \\
\hline 1 & 3 & $\mathrm{X}$ & Positivo \\
2 & 20 & $\mathrm{X}$ & Positivo \\
3 & 25 & $\mathrm{X}$ & Negativo \\
4 & 18 & $\mathrm{X}$ & Positivo \\
5 & 12 & $\mathrm{X}$ & Negativo \\
6 & 20 & $\mathrm{X}$ & Positivo \\
7 & 22 & $\mathrm{X}$ & Positivo \\
8 & 7 & $\mathrm{X}$ & Positivo \\
9 & 20 & $\mathrm{O}$ & $\mathrm{O}$ \\
10 & 10 & $\mathrm{O}$ & $\mathrm{O}$ \\
\hline
\end{tabular}

X: houve resposta ao implante intravaginal de progesterona. O: não houve resposta ao implante intravaginal de progesterona.

Durante a execução do trabalho observou-se que 2 éguas permaneceram em anestro, portanto não responderam ao tratamento, sendo uma delas de 10 e outra de 20 anos. Porem, ao analisar os dados como um todo percebeu-se que a faixa etária das éguas não influenciou a eficácia do implante, já que éguas com idade variando entre 3 e 25 anos foram responsivas ao tratamento.

Lima et al. (2000), analisaram 120 ciclos estrais de éguas com o objetivo de estudar o efeito do número de inseminações artificiais por ciclo sobre a fertilidade de éguas inseminadas com sêmen 
resfriado, concluindo que a taxa de concepção ao primeiro ciclo foi de 47,83\% com uma inseminação artificial (IA) e 70\% com duas. Sendo que, segundo Peres et al. (2006), o primeiro folículo ovulatório do ano produz óvulos viáveis para a recuperação de embriões.

Os dados obtidos com o uso de implante intravaginal de progesterona resultaram em relevante eficácia e taxa de concepção, pois conseguiu-se $75 \%$ de embriões viáveis nas éguas (tabela 2). Porém, no presente experimento, não houve grupo testemunho para comparar esse dado, necessitando assim de estudos mais abrangentes a respeito da técnica apresentada.

\section{CONCLUSÃO}

Nas condições do presente experimento, concluiu-se que o implante intravaginal de progesterona foi eficaz, demonstrando $80 \%$ de eficácia sobre a ciclicidade das éguas em anestro e conseguindo $75 \%$ de embriões viáveis. Pode concluir, também, que a faixa etária das éguas não influenciou na eficácia do implante.

\section{REFERÊNCIAS}

ARBEITER, K.; BARTH, U.; JÖCHLE, W. Observations on the use of progesterone intravaginally and of deslorelin STI in acyclic mares for induction of ovulation. Journal of Equine Veterinary Science, v.14, p.21-25, 1994.

BARTOLI, E. M. Uso de gonodatrofina coriônica humana no controle reprodutivo de éguas. 2009. 25f. Monografia de Conclusão de Curso (Graduação em Medicina Veterinária). Centro Universitário das Faculdades Metropolitanas Unidas. São Paulo.

BEREZOWSKI, C. J.; STITCH, K. L.; WENDT, K. M. Clinical comparison of 3 products available to hasten ovulation in cyclic mares. Journal of Equine Veterinary Science, v.24, p.231-233, 2004.

CARMO, M. T. et al. Use of intravaginal progesterone implant to hasten the season in transitional mares. 2009. INTERNATIONAL CONGRESS OF THE WORLD EQUINE VETERINARY

ASSOCIATION, 11. Disponivel em: <http://www.ivis.org>. Acesso: 15 out.2010.

CARNAVALE, E. M.; GINTHER, O. J. Age and pasture effects on vernal transition in mares.

Theriogenology, v.47, p.1009-1018, 1997.

DAELS, P. F. The spring-transition: diagnosis and management. 2004. CONGRESSO NAZIONALE MULTISALA SIVE, 10. Disponível em:

<http://www.ivis.org/proceedings/SIVE/2004/lectures/daels4.pdf>. Acesso: 5 ago. 2010.

FERREIRA, H. O.et al. Dinâmica folicular em éguas submetidas ao dispositivo de liberação de progesterona intra-vaginal: resultados preliminares. 2009. CONCCEPAR - CONGRESSO CIENTÍFICO DA REGIÃO CENTRO-OCIDENTAL DO PARANÁ, 3. Disponível em: http://www.grupointegrado.br/conccepar2009/?pg=anais_resumo\&codigo=276 . Acesso: 5 ago. 2010.

GINTHER, O. J. Reproductive biological of the mare: basic and applied aspects. 2.ed. Wisconsin: Equiservices, Cross Plains, 1992. 640p. 
GUILLAUME, D.; PALMER, E. Effect of oral melatonin on the date of the first ovulation after ovarian inactivity in mares under artificial photoperiod. Journal of Reproduction and Fertility. Suppl.44, p.249257, 1991.

HAETINGER, C.et al. Uso comparativo de progesterona sintética P4 e PGF2 $\alpha$ na sincronização de cio em éguas da raça crioula. 2008. CONGRESSO DE INICIAÇÃO CIENTIFICA DA UNIVERSIDADE FEDERAL DE PELOTAS, 17. Disponível em:

http://www.ufpel.edu.br/cic/2008/cd/pages/pdf/CA/CA_01004.pdf . Acesso: 02 dez. 2010.

KUBIAK, J. R.et al. The influence of energy intake and percentage of body fat on the reproductive performance of nonpregnant mares. Theriogenology, v.28, p.587-598, 1987.

LIMA, M. C. C.et al. Efeito do número de inseminações artificiais por ciclo sobre a fertilidade de éguas inseminadas com sêmen equino diluído, resfriado a $20^{\circ} \mathrm{C}$ e transportado. Revista Brasileira de Zootecnia, v.29, n.6, p.1649-1653, 2000.

NUNES, M. M.et al. Influence of the autumn transitional phase on follicular development in mares. Theriogenology, v.58, p.603-606, 2002.

PERES, K. R.; LANDIM-ALVARENGA, F. C.; ALVARENGA, M. A. Utilização do primeiro ciclo ovulatório da estação reprodutiva para produção de embriões em éguas sob condições tropicais. Brazilian Journal of Veterinary Research and Animal Sciense, v.43, n.2, p.270-279, 2006.

SQUIRES, E. L. Hormonal manipulation of the mare. Journal of Equine Veterinary Science, v.28, p.627-634, 2008. 
